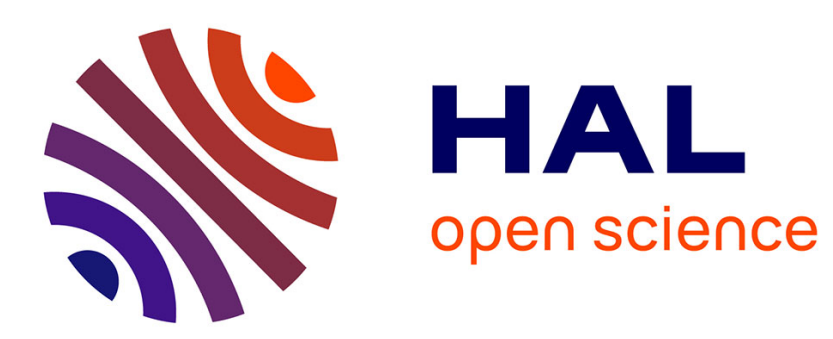

\title{
Enantioselective acylation of R-2-pentanol in a solid/gas reactor catalysed by lipase $B$ from Candida antarctica.
}

\author{
Valérie Léonard, Sylvain Lamare, Marie-Dominique Legoy, Marianne Graber
}

\section{To cite this version:}

Valérie Léonard, Sylvain Lamare, Marie-Dominique Legoy, Marianne Graber. Enantioselective acylation of R-2-pentanol in a solid/gas reactor catalysed by lipase B from Candida antarctica.. Journal of Molecular Catalysis B: Enzymatic, 2004, 32, pp.53-59. hal-00329728

\section{HAL Id: hal-00329728 \\ https://hal.science/hal-00329728}

Submitted on 13 Oct 2008

HAL is a multi-disciplinary open access archive for the deposit and dissemination of scientific research documents, whether they are published or not. The documents may come from teaching and research institutions in France or abroad, or from public or private research centers.
L'archive ouverte pluridisciplinaire HAL, est destinée au dépôt et à la diffusion de documents scientifiques de niveau recherche, publiés ou non, émanant des établissements d'enseignement et de recherche français ou étrangers, des laboratoires publics ou privés. 
Enantioselective acylation of R-2-pentanol in a solid/gas reactor catalysed by lipase B from Candida antarctica.

Valérie LEONARD, Sylvain LAMARE, Marie-Dominique LEGOY and Marianne GRABER*

Université de la Rochelle, Laboratoire de Biotechnologies et Chimie Bio-organique, Pôle Sciences et Technologies, Bâtiment Marie Curie, Avenue Michel Crépeau, 17042 La Rochelle, Cedex 1, France

*Corresponding author: $\quad$ Dr. Marianne GRABER,

tel: 33546458630 , fax: 33546458265 ,

Email:mgraber@univ-lr.fr 


\section{ABSTRACT}

The feasibility of the enzymatic enantioselective acylation of R-2-pentanol in a solid/gas reactor was demonstrated and compared to the same reaction carried out in liquid systems. This reaction was catalysed by lipase B from Candida antarctica (CALB) through transesterification of methyl propionate and R-2-pentanol. In the present study we show that there is no effect of the organic solvent on the enantioselectivity E of CALB for this reaction neither in the solid/gas system nor in organic liquid medium. The innovative idea of this work is the replacement of the substrates and solvent concentrations by their thermodynamic activities in order to correct the differences of substrates solvation in the different media studied and to control the level of availability of the different chemical species for the enzyme. Finally, we established that the solid/gas bioreactor is a suitable tool to study the influence of organic components on the enantioselectivity of lipases because it permits to control and adjust independently thermodynamic activities of substrates, on the one hand, and of an extra-added organic component on the other hand.

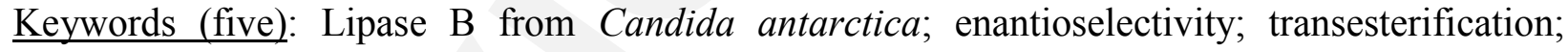
organic solvent; solid/gas biocatalysis. 


\section{INTRODUCTION}

Chiral drugs, agrochemical, food additives and fragrances represent classes of compounds with high economic and scientific potential. The demand for enantiopure compounds is expected to dramatically increase [1], the pharmaceutical industry being the main contributor and driving force of this tendency.

Indeed, for racemic mixture when administered as a drug, very often, one of the enantiomer only is biologically active while the other one might contribute to side-effects, displaying toxicity, or acting as antagonist $[2,3]$. Therefore requirements for chiral drugs are now very hard to fulfil since safety and tolerability of both enantiomers has to be demonstrated before the development of racemic medicine can be envisaged. As a consequence, the development of techniques of enantioseparation have been developed and progressed over the last two decades [4]. An alternative for preparation of optically active compounds is to proceed through biological transformation, since stereoselectivity is often a characteristic feature of enzymatic reactions and metabolic processes.

Lipases (triacylglycerol ester hydrolases, E.C. 3.1.1.3.) can accept substrates of wide structure (lipids, sugars, alcohols, acids, esters...) and can catalyse enantio-, chemo- and regioselective reactions. Their ability to retain activity and selectivity in non-conventional media has enabled their use as biocatalysts to dramatically expand in enantioselective synthetic reactions.

Among the most used lipases for synthesis or resolution of racemates, lipase B from Candida antarctica (CALB) presents the advantage to display a relatively known catalytic and enantioselective mechanism [5-8]. This enzyme is highly enantioselective for enantiomers of secondary alcohols [6, 9-12]. From knowledge of enzyme structure, the origin of this enantioselectivity can be attributed to the physical restriction of the active site, the existence of a stereospecific pocket, the presence of a long and hydrophobic tunnel at the entrance of the active site and to specific bindings stabilising the tetrahedral intermediates [7, 13]. From results from literature, it appears that CALB has an enantiopreference for $\mathrm{R}$ enantiomers of secondary 
alcohols with E values being strongly influenced by substrates structural characteristics. As far as the model from Kazlauskas et al. (1991) is considered [14], results from literature suggest that for secondary alcohol substrates of $\mathrm{M}$ substituent having a carbon linear chain less than $2 \mathrm{C}$, with double or triple linkages and $\mathrm{L}$ substituent with more than two carbon, with a ramified chain, an halogen atom or a cyclic structure, E values are likely to be higher than 100 [15]. This conclusion would therefore enable to predict CALB enantiopreference for new substrates or to increase enantioselectivity by substrate engineering.

Another way to change the selectivity of an enzyme-catalysed reaction is to change the reaction conditions, such as temperature [16] and reaction medium [17]. Substrate specificity [18] and enantiopreference [17] of enzymes can be greatly affected, even reversed, by solvent engineering.

Several solvent characteristics have been shown to correlate with the enantiomeric ratio E. The most studied are:

-the solvent polarity, measured as $\log P$ where $P$ is the partition coefficient of the solvent between octanol and water, -the solvent dipole moment and the solvent dielectric constant, -the size of the solvent molecule measured as the van der Waals volume.

For example, a correlation between the solvent's dielectric constant and the enantiomeric ratio was observed by Fitzpatrick and Klibanov in 1991, when subtilisin was used to resolve ( \pm )-1phenylethanol by transesterification with vinyl butyrate. Results suggest that enzyme's enantioselectivity decreases as the solvent's dielectric constant increases [19]. Sometimes, a change of solvent can lead to an inversion of enzyme's enantioselectivity. Such an example was reported by Tawaki and Klibanov in 1992 for the Aspergillus oryzae proteasecatalysed transesterification of N-acetyl- (L or D)-phenylalanine chloroethylester [N-Ac- (L or D)-Phe-OEtCl] with 1-propanol [17]. A similar reversal of enantioselectivity was observed for Candida cylindracea lipase-catalysed esterification of $( \pm)$-2-phenoxy propionic acid with 1- 
butanol according to Ueji and al. in 1992 [20]. Other authors observed no correlation whatever the parameters studied like Bovara and al. in 1991 for the resolution of $( \pm)$-trans-sobrerol by transesterification with vinyl acetate catalysed by lipase PS [21] or like Secundo and al. in 1992 for the resolutions of $( \pm)$-sulcatol and ( \pm )-3-bromo-5-hydroxymethyl isoxazoline by transesterification with trifluoroethyl butanoate by lipase PS and porcine pancreatic lipase [22]. As far as CALB is concerned, the general trends concerning variation of $\mathrm{E}$ with $\log P$ is that $\mathrm{E}$ decreases while increasing $\log P$ [23-25]. However, other studies observe complete lack of correlation [26] or bell-shaped relations [10] between these two parameters. In a more recent work, Ottosson et al. (2001) showed a good correlation between the Van der Waals volume of the solvent molecules and the enantiomeric ratio in various solvents and in supercritical carbon dioxide for the resolution of 3-methyl-2-butanol catalysed by CALB [27]. Results suggest that the larger the size of the solvent molecule, the higher the enantioselectivity and vice versa. In conclusion, it appears that no general rule of the effect of solvent on enantioselectivity of enzymes can be established and that the effects of other parameters having an influence on enantioselectivity (temperature, type of substrates etc) are linked together and may modify the effect of solvents.

In this paper, resolution of racemic 2-pentanol through transesterification catalysed by CALB both in liquid phase and in the gas phase is reported. S-2-Pentanol is a chiral intermediate in the synthesis of several potential anti-Alzheimer's drugs that inhibit $\beta$-amyloid peptide release and/or its synthesis [28]. Enantioselective acylation of R-2-pentanol has been successfully realised in the organic phase [29]. The present study demonstrates the feasibility of such reaction in the gas phase and allows a comparison of the E values obtained in liquid and gaseous media. Finally the advantages of the solid/gas technology as a tool for studying the influence of the microenvironment on enzyme enantioselectivity are explained. 
Indeed, this technology which permits to fix and control independently all the thermodynamics parameters of the enzyme microenvironment should lead to the possible rationalization of the determining factors of enantioselectivity.

\section{EXPERIMENTAL}

\section{Enzyme and chemicals}

CHIRAZYME ${ }^{\circledR}$ L-2, Lyo (Type B lipase from C. antarctica lyophilised) was a gift from Roche Industry (Penzberg, Germany).

All substrates were of the highest purity (99\% minimum) and checked by gas chromatography before use. Chemicals were dried prior to use. Substrates and solvents were purified and stored under argon atmosphere and over molecular sieves.

(R,S)-pentan-2-ol propionate was synthesised from pentan-2-ol and propionic acid in the presence of PTSA.

\section{Chemical Synthesis. General Procedure.}

Organic solvents were purified when necessary by methods described by D.D. Perrin [30] or purchased from Aldrich Chimie. All solutions were dried over anhydrous magnesium sulfate and evaporated on a Büchi rotatory evaporator. All anhydrous reactions were performed in ovendried glassware under an atmosphere of argon.

\section{(R,S)-Pentan-2-ol propionate synthesis}

Under an inert atmosphere of argon, a solution of pentan-2-ol $(80 \mathrm{~mL}, 735 \mathrm{mmol}, \mathrm{Bp}=118$ $119^{\circ} \mathrm{C}$ at $\left.760 \mathrm{~mm} \mathrm{Hg}, \mathrm{nD} 20=1,405-1,407\right)$ and propionic acid $\left(50 \mathrm{~mL}, 668 \mathrm{mmol} \mathrm{Bp}=141^{\circ} \mathrm{C}\right.$ at $760 \mathrm{~mm} \mathrm{Hg}, \mathrm{nD} 20=1,385-1,387)$ was heated in the presence of a catalytic amount of PTSA, under reflux $\left(150^{\circ} \mathrm{C}\right)$ during 6 hours. The mixture was allowed to cool and successively washed 
with saturated aqueous $\mathrm{NaHCO}_{3}$ and brine. The organic layer dried with $\mathrm{MgSO} 4$ was filtered. The filtrate was purified by distillation and stored over molecular sieves. The obtained racemic was used for internal calibration on GC.

\section{Adsorption of lipase onto a solid support.}

Enzyme adsorption was performed onto Chromosorb P AW DMCS; mesh 60-80 (Acid Washed DiMethylChloroSilanized) (Varian, France). In a typical adsorption procedure for solid-gas

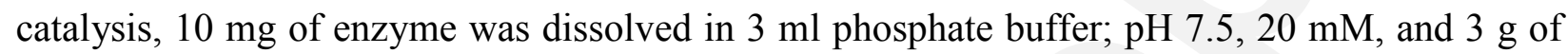
dry Chromosorb P AW DMCS were added to the solution. In a typical adsorption procedure for organic phase catalysis, $500 \mathrm{mg}$ of enzyme was dissolved in 1,5 $\mathrm{ml}$ phosphate buffer, $\mathrm{pH}$ 7,5, 20 $\mathrm{mM}$, and 1,5 g of dry Chromosorb P AW DMCS were added to the solution. After vigorous shaking, the preparations were left 1 week under vacuum and over $\mathrm{P}_{2} \mathrm{O}_{5}$ at room temperature.

\section{Experimental setup for solid-gas catalysis}

The bioreactor used in this study has already been described in a previous publication [31]. The packed bed bioreactor itself was composed of a $9 \mathrm{~cm}$ long glass tube (6 mm O.D., $4 \mathrm{~mm}$ I.D.) in which a known mass of the enzymatic preparation was packed between two glass wool layers. Substrate or solvent feeding was done by passing dried nitrogen, as carrier gas, through the substrate/solvent flasks. Substrates and solvent were continuously flown through the bioreactor, reacting with the lipase. Thermodynamic activities of these compounds in the reactor are defined as the ratio of their partial pressure in gas entering the bioreactor to their saturation pressure at the working temperature. The desired thermodynamic activities were obtained by adjusting the volumetric flows of the carrier gas in the different lines at appropriate values, according to the calculations explained previously [31]. Calculations were performed considering that the gas was close to an ideal one. Then fugacity was not taken into account. The gas leaving the bioreactor 
was injected into a gas chromatograph for analysis. Acquisition and control of parameters (volumetric flows, molar flows, substrate and solvent thermodynamic activities, partial pressures, temperatures) were monitored on-line using an IBM personal computer.

A typical experiment was run at $45^{\circ} \mathrm{C}$, with $5 \mathrm{mg}$ of immobilised enzyme and the total flow passing through the reactor was set at $1,3 \mathrm{mmol} \cdot \mathrm{min}^{-1}$. This flow as well as the quantity of enzyme and thermodynamic activities of substrates were adjusted so that initial rates were measured.

\section{Experimental setup for organic phase synthesis}

Transesterification reactions run in organic media were carried out using $1 \mathrm{mg} \mathrm{ml}^{-1}$ of immobilised enzyme so that initial rates were measured.

Reaction mixtures were composed of the two substrates (pentan-2-ol and methyl propionate) and a solvent. The quantities of substrates available for the enzyme were expressed in term of thermodynamic activities. These parameters were obtained by using activity coefficients for each component, calculated from molar fractions thanks to the UNIFAC group contribution method [32].

The mixture was incubated at $45^{\circ} \mathrm{C}$ for $50 \mathrm{~min}$. under magnetic stirring and samples were taken at intervals. Samples were then treated in order to remove the biocatalyst by centrifugation and cooled prior to their analysis by gas chromatography.

\section{Chromatographic assays}

For the solid/gas system analyses, the vapour phase leaving the bioreactor was sampled using a $0.25 \mathrm{~mL}$ loop on a six-way valve (Valco) maintained at $150^{\circ} \mathrm{C}$. Samples were automatically injected in the split injector of a gas chromatograph (Hewlett Packard model 5890 A) equipped with a flame ionization detector (FID) for detection of all products. The column used was a 
Chirasil-Dex CB composed of $\beta$-cyclodextrin $(25 \mathrm{~m}$ x $0.25 \mathrm{~mm}$ i.d. x $0.25 \mu \mathrm{m}$ film thickness, Chrompack, France). The injector and the detector were kept at $220^{\circ} \mathrm{C}$ and $250^{\circ} \mathrm{C}$ respectively. The column temperature was programmed to hold $15 \mathrm{~min}$. at $55^{\circ} \mathrm{C}$ then to increase at $3{ }^{\circ} \mathrm{C} \cdot \mathrm{min}^{-1}$ from $55^{\circ} \mathrm{C}$ to $85^{\circ} \mathrm{C}$ and to hold $5 \mathrm{~min}$. at $85^{\circ} \mathrm{C}$. Carrier gas was nitrogen and the flow rate in the column was $1 \mathrm{~mL} \cdot \mathrm{min}^{-1}$. The split flow was $81 \mathrm{~mL} \cdot \mathrm{min}^{-1}$. Hydrogen and air were supplied to the FID at 50 and $324 \mathrm{~mL} \cdot \mathrm{min}^{-1}$ respectively. Quantitative data were obtained after integration on a HP 3396A integrator.

The external calibration of the two substrates (pentan-2-ol and methyl propionate ) was carried out by programming a range of their partial pressures in the bioreactor and by analysing with the gas chromatograph. For the products (methanol and propionate of pentan-2-ol), an internal calibration was carried out by using the pentan-2-ol and the methyl propionate as internal standards.

For accurate determination of $\mathrm{E}$ values the vapour phase leaving the bioreactor was recondensed for a period of time depending on the molar flows applied, and were then partially evaporated in order to enhance 2-pentyl esters detection and quantification. Evaporation of samples was also performed for reactions carried out in liquid systems if necessary. Then, a large part of solvent (which have boiling points below $103^{\circ} \mathrm{C}$ ) and unreacted methyl propionate (boiling point $=78$ $79^{\circ} \mathrm{C}$ ) were eliminated. Enrichment of product reaction then enables accurate measurement of the enantiomeric ratio considering that $\mathrm{E}$ is not affected because:

-The boiling point of propionate of pentan-2-ol is $170^{\circ} \mathrm{C}$ so its evaporation is negligible.

-The insignificant evaporation of ester of pentan-2-ol is similar for the two enantiomers because enantiomers have, by definition, the same boiling points. After this treatment the samples could be analysed by the gas chromatograph.

For the analyses after reactions run in organic phase, another gas chromatograph (Agilent model 6890 N Series) equipped with a FID was used. The column, the carrier gas, the flow rate in the 
column and the injector and detector's temperatures were the same as the one described previously. The split flow was decreased to $20 \mathrm{~mL} \cdot \mathrm{min}^{-1}$ and hydrogen and air were supplied to the FID at 35 and $350 \mathrm{~mL} \cdot \mathrm{min}^{-1}$ respectively. The initial temperature $\left(55^{\circ} \mathrm{C}\right)$ was maintained 15 min. then programmed to increase at $3^{\circ} \mathrm{C} \cdot \min ^{-1}$ to $85^{\circ} \mathrm{C}$ and finally held $1 \mathrm{~min}$. at this temperature. The initial pressure $(60 \mathrm{KPa})$ was maintained $14 \mathrm{~min}$. then programmed to increase at $4 \mathrm{KPa} \cdot \mathrm{min}^{-1}$ to $100 \mathrm{KPa}$ and finally held $1 \mathrm{~min}$. at this pressure. Quantitative data were obtained after integration on an Agilent 3396 Series III integrator. Heptane was used as internal standard.

Elution peaks of R- and S-pentan-2-ol were identified on GC chromatogram using pure commercial R- pentan-2-ol.

To identify the $\mathrm{R}$ enantiomer of sec-pentyl propionate from the $\mathrm{S}$ enantiomer, two transesterification reactions using either $5 \mu \mathrm{l}$ R-pentan-2-ol or $5 \mu \mathrm{l}$ racemic pentan-2-ol as alcohol substrate and $30 \mu \mathrm{l}$ methyl propionate as acyl substrate were run in $3 \mathrm{ml}$ octane. The reaction was catalysed with $20 \mathrm{mg}$ Novozym during $20 \mathrm{~min}$ at a temperature of $70^{\circ} \mathrm{C}$. Samples were taken and analysed on GC as described above. The chromatograms obtained enabled retention times for each enantiomers of sec-pentyl propionate to be determined. It also permitted to check that the lipase has an enantiopreference for the R-enantiomer.

\section{Determination of the enantiomeric ratio $E$}

The enantiomeric ratio was calculated using the equation from Wescott and Klibanov (1993) [18]:

$\mathrm{E}=\mathrm{Vi}^{\mathrm{R}} / \mathrm{Vi}^{\mathrm{S}}$ $\mathrm{Vi}^{\mathrm{R}}$ and $\mathrm{Vi}^{\mathrm{S}}$ are the initial rates of R-pentan-2-ol and S-pentan-2-ol respectively.

Methyl propionate thermodynamic activity was fixed at 0.1 in the solid/gas reactor in order to allow complete acylation of free enzyme[33]. This assumption was verified by checking that $\mathrm{E}$ 
obtained in gas at $\mathrm{a}_{\text {methyl propionate }}=0.1$ was equal to $\mathrm{E}$ obtained at higher values of $\mathrm{a}_{\text {methyl propionate }}$ and that acylation of the free enzyme was not a limiting step for the transesterification reaction.

\section{RESULTS AND DISCUSSION}

\section{Feasibility of enantioselective acylation of R-2-pentanol in the solid-gas bioreactor.}

From a previous work kinetic results for the alcoholysis of methylpropionate with n-propanol in a continuous solid/gas bioreactor showed that the initial reaction rates fitted well a Ping Pong Bi Bi mechanism with competitive inhibition by the alcohol. Even if mechanism determination cannot rest on kinetic data alone, these results strongly suggest that the mechanism of lipasecatalysed alcoholysis remains unchanged when using lipase with gaseous substrates [34].

In the present work we compared enantioselectivity of lipase B from Candida antarctica in organic liquid medium and in the solid/gas bioreactor.

The enantiomeric ratio measured in the solid/gas reactor in the sole presence of substrates $\left(a_{\text {pentan- }}\right.$ 2-ol $=0,05$ and $\left.\mathrm{a}_{\text {methyl propionate }}=0,1\right)$ with nitrogen as carrier gas was equal to $176 \pm 13$. Measurement of E was performed in different organic liquid media, containing the two substrates pentan-2-ol and methyl propionate $\left(\mathrm{a}_{\text {pentan-2-ol }}=0,04\right.$ and $\left.\mathrm{a}_{\text {methyl propionate }}=0,8\right)$ and an added solvent at low thermodynamic activity $\left(\mathrm{a}_{1,4 \text {-dioxane }}=0,17\right.$ in the first case, $\mathrm{a}_{2 \text {-methyl-2-butanol }}=0,31$ in the second case, and $a_{\text {hexane }}=0,31$ in the third case). Results obtained for E were respectively equal to $192 \pm 21,196 \pm 12$, and $186 \pm 19$.

It thus appears that the enantioselectivity of the lipase B from Candida antarctica for the reaction studied is similar in organic liquid medium and in the solid/gas bioreactor in absence of water for both systems. 
Influence of the type and the thermodynamic activity of solvent on lipase enantioselectivity.

The resolution of pentan-2-ol catalysed by Candida antarctica lipase B, was studied with addition of five different organic compounds in solid/gas bioreactor (2-methyl-2-butanol (2M2B), hexane, 1,4-dioxane, acetone, cyclopentane) and in three organic solvents in liquid medium (2M2B, hexane, 1,4-dioxane). These components were chosen in order to cover:

-a large range of hydrophobicity, measured as $\log \mathrm{P}$, as this parameter was shown to have an influence on enzyme enantioselectivity [10, 23-25] (Table1),

-a large range of size, measured as the van der Waals volume of the solvent molecules, since Ottosson and Hult (2001) obtained a correlation between this parameter and CALB enantioselectivity [27] (Table 1).

However, compared with these recent publications, the innovative idea in the present study is the replacement of concentrations of substrates and solvent by their thermodynamic activities. This method appears useful for correcting solvation effects of the different components of the system. Indeed, when a comparison of enzyme behaviour in different solvents has to be made, the "availability of substrate to the enzyme" cannot be quantified using its concentration mainly because substrate solvation is modified as the reaction medium changes [35, 36].

To take into account such corrections in liquid media, activity coefficients ( $\gamma$ values) of substrates are needed. In our study they are estimated by using the UNIFAC group contribution method $[32,37]$. When performing studies concerning the effect of solvent on kinetic parameters of enzymes, with correction for solvation of substrates, authors frequently call UNIFAC predictions into question, as sources of inaccurate $\gamma$ values, being the cause of differences in enzyme performance observed in various solvents [37-39]. Deviations in the UNIFAC calculations up to a factor of 2 have been reported [38], rendering correction for solvation of substrates far from being straightforward. 
Contrary to liquid systems, the gas phase reactor offers the possibility to control and adjust perfectly thermodynamic activities of reaction species, on the one hand, and of an extra-added component on the other hand, by varying the partial pressure of each compound in the carrier gas. Problems encountered in studies performed in liquid organic media, to evaluate differences in solvation of the substrates, in particular in determining activity coefficients, are therefore avoided.

Then, E was determined in presence of the different components listed above at a constant thermodynamic activity of 0.3 , both in the solid/gas reactor and in liquid medium. Results obtained are shown on Figure 1.

The average of the nine $\mathrm{E}$ values obtained in presence of the different organic components either in gas or in liquid phase and in gas without any added component in the gas phase, is equal to $188 \pm 15$. This corresponds to a relative difference between the $\mathrm{E}$ values obtained in all the experiments of $8 \%$. This value appears much lower than relative differences obtained in other studies. For example, results reported by Ottosson and Hult [27] showed that the average of the eight $\mathrm{E}$ values obtained in liquid phase in presence of the eight different organic components (decaline $(\mathrm{E}=890)$, hexane $(\mathrm{E}=810)$, cyclopentane $(\mathrm{E}=820)$, 1,4-dioxane $(\mathrm{E}=580)$, tetrahydrofuran $(E=710)$, acetone $(E=650)$, dicholoromethane $(E=580)$ and carbon disulfide $(\mathrm{E}=600))$ is equal to $705 \pm 122$. This corresponds to a relative difference between the eight $\mathrm{E}$ values obtained of $17 \%$. Moreover, in supercritical carbon dioxide without any addition of solvent molecules, a much lower $\mathrm{E}$ value was obtained $(\mathrm{E}=330)$ by the same authors while in the solid gas system, the E value obtained in absence of non reacting molecule was similar to what was obtained in liquid system.

Then, we did not find any real effect of the type of solvent on the enantioselectivity of the lipase B from Candida antarctica for the studied reaction.

Complementary studies in the solid/gas bioreactor were performed in the presence of higher thermodynamic activities of solvents. Then, in the presence of 2M2B, hexane, 1,4-dioxane, 
acetone, or cyclopentane, E values were determined for four thermodynamic activities of organic components equal to 0,3, 0,5, 0,6 and 0,7. Results are shown on Figure 2 and summarized in Table 2.

On inspecting the values on Table 2 it appears that the relatives differences between the four E values for each organic component, corresponding to four different thermodynamic activities of the organic component, are still very low (around 9\%).

As a result, this relatively low difference is consistent to affirm that the level of availability of solvent has no effect on the enantioselectivity of CALB in the case of this particular alcoholysis reaction.

\section{CONCLUSION}

Further investigations are currently in progress with others achiral acyl donors with longer acyl chains. Indeed, in a recent study Ottoson and Hult (2001) showed that the enantioselectivity, E, of Candida antarctica lipase B (CALB) was strongly influenced by the chain length of the achiral acyl donor employed in the transesterification of 3-methyl-2-butanol [40]. These authors explained that CALB has a deep narrow active site into which the substrate ester binds in a hairpin structure [8]. The acyl and alcohol moieties are thereby brought close in space during catalysis, which could explain CALB's sensitivity to the acyl chain length.

Because solvent molecules can be present in the active site and can modify bindings of bigger substrates, effect of solvent availability on E values could be obtained with longer chain acyl donors.

Then, this work constitutes the starting point for a series of experiments performed in solid/gas catalysis, concerning the effect of non reactant organic species on enantioselectivity of lipases, since the solid/gas technology enables an accurate thermodynamic approach for studying the effect of the microenvironment on enzymatic activity and specificity. Besides the feasibility of enzymatic enantioselective reaction in a solid/gas reactor was demonstrated and our results seem 
to indicate that the very fact that the lipase works in the gaseous phase does not modify its enantioselectivity. This last point would allow to generalise results obtained in solid/gas to other types of reaction media.

Furthermore solid/gas catalysis appears probably as the most appropriate and the most complementary experimental tool for validating molecular modelization experiments.

Molecular modelling experiments, taking the solvent molecules into account, are envisaged and might give better understanding of the experimental results. This could provide interesting informations about the positioning of solvent molecules in the active site of the enzyme and about interactions between these molecules and the amino-acids of the active site.

Studies with genetically modified lipases are also envisaged and should also help for the understanding of the effect of solvent on the enantioselectivity of this class of enzymes. 


\section{Legend of Figures:}

Figure 1: Influence of the type of solvent on the enantiomeric ratio for a thermodynamic activity of solvent equal to 0,3 .

- For the reaction in the solid/gas bioreactor: $\left(a_{\text {pentan-2-ol }}=0,05\right.$ and $\left.\mathrm{a}_{\text {methyl propionate }}=0,1\right)$.

- For the reaction in liquid medium: $\left(a_{\text {pentan-2-ol }}=0,04\right.$ and $\left.\mathrm{a}_{\text {methyl propionate }}=0,8\right)$ for $2 \mathrm{M} 2 \mathrm{~B}$;

$\left(a_{\text {pentan-2-ol }}=0,04\right.$ and $\left.\mathrm{a}_{\text {methyl propionate }}=0,8\right)$ for hexane. . $\left(a_{\text {pentan-2-ol }}=0,03\right.$ and $\left.\mathrm{a}_{\text {methyl propionate }}=0,68\right)$ for 1,4-dioxane.

Figure 2: Influence of the quantity of solvent on the enantiomeric ratio.

These experiments were made in the solid/gas bioreactor, $\left(\mathrm{a}_{\text {pentan-2-ol }}=0,05\right.$ and $\mathrm{a}_{\text {methyl }}$ propionate $=0,1)$.

\section{Solvent studied:}
A: acetone.
B: cyclopentane.
C: 2-methyl-2-butanol.
D: 1,4-dioxane.
E: hexane. 
Figure1:

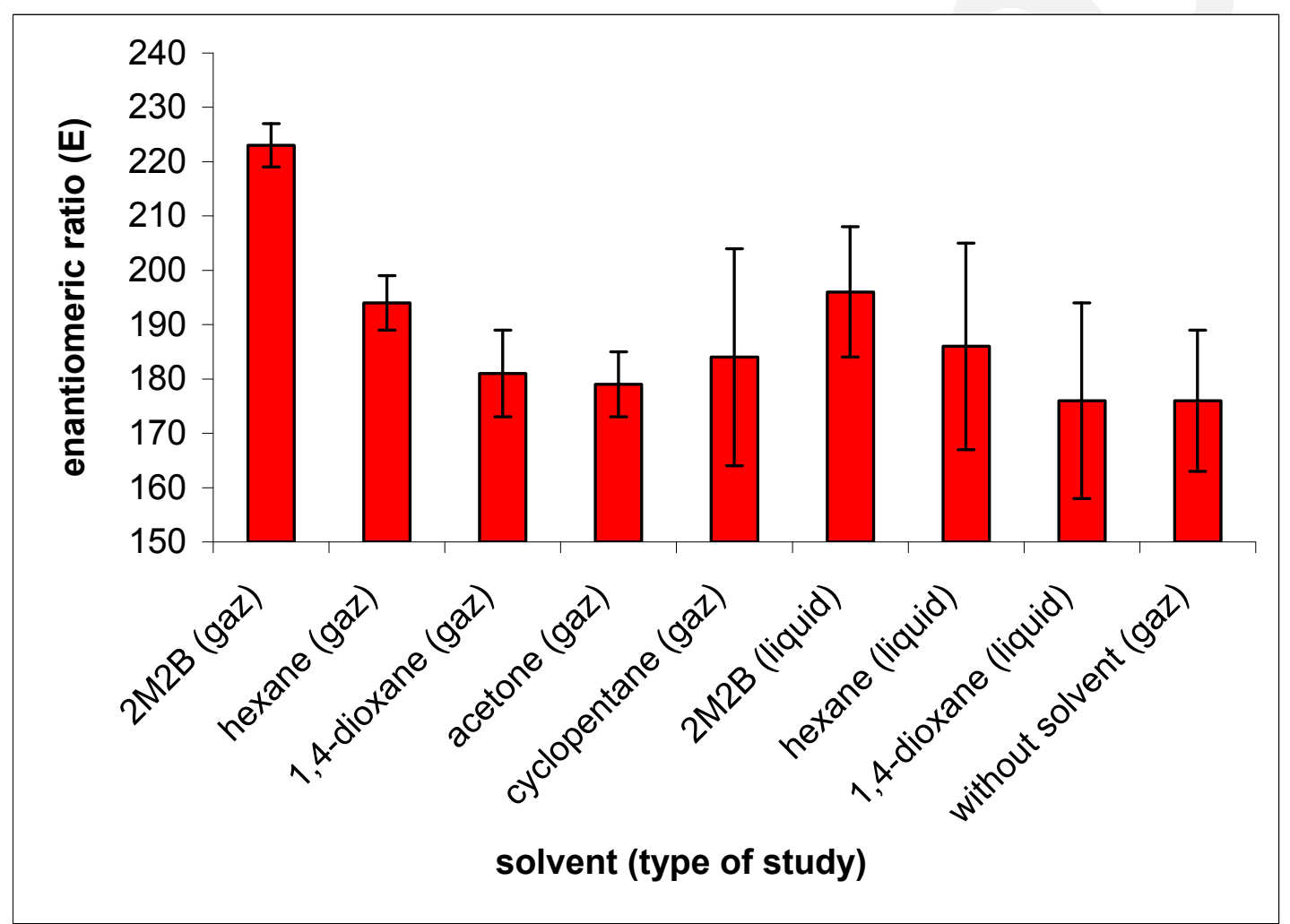




\section{Figure 2:}
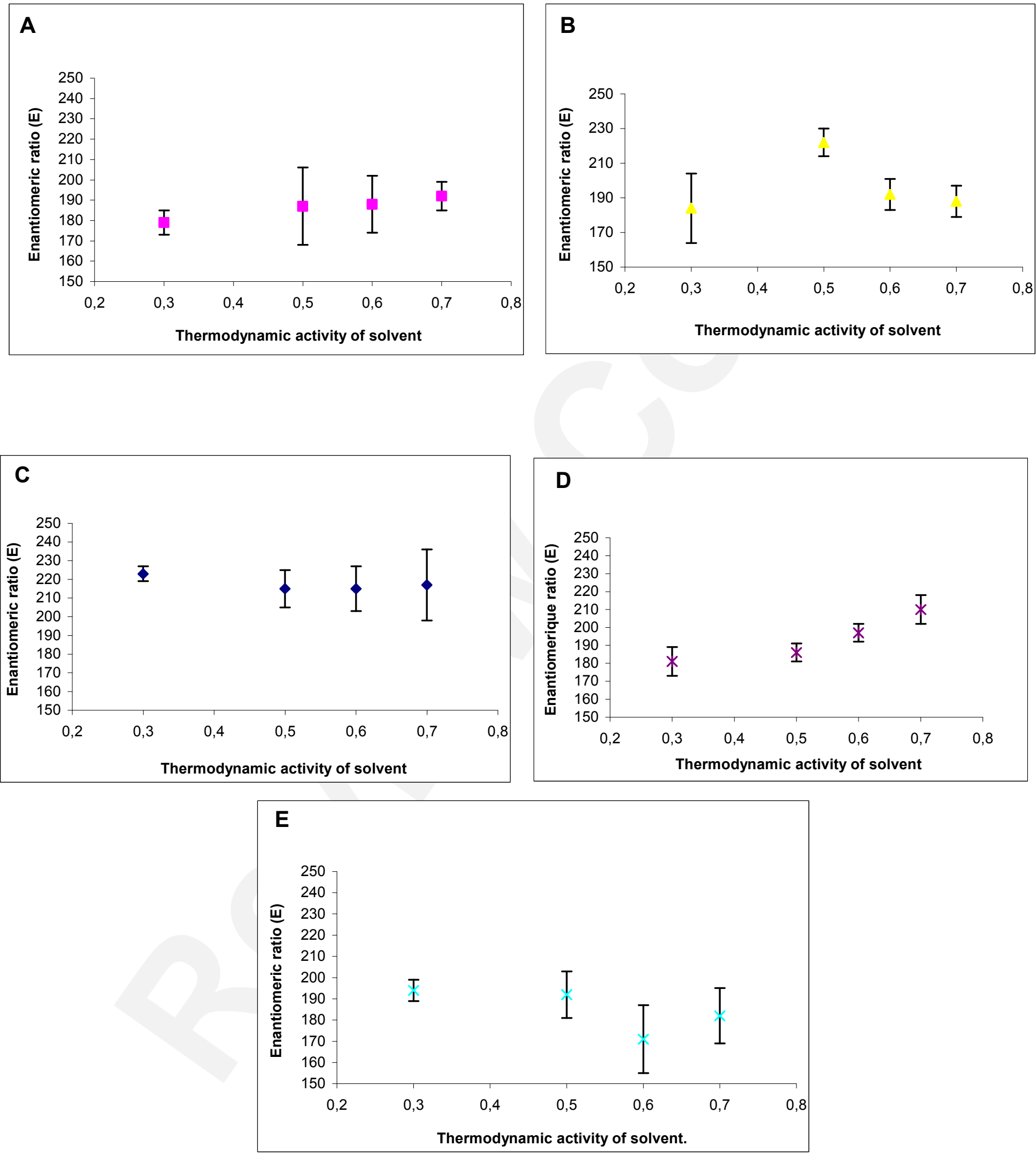
Table 1 : $\log \mathrm{P}$ and van der Waals volume of the solvents chosen. ${ }^{\mathrm{a}}$ from Ottosson and Hult (2001).

\begin{tabular}{|c|c|c|}
\hline Solvent & Log P & Volume $\left(\AA^{\mathbf{3}}\right)$ \\
\hline hexane & 3,5 & $109^{\mathrm{a}}$ \\
\hline cyclopentane & 3 & 82 \\
\hline 2-methyl-2-butanol & 0,89 & NA \\
\hline acetone & $-0,23$ & 60 \\
\hline 1,4-dioxane & $-1,1$ & 80 \\
\hline
\end{tabular}


Table 2: : Influence of the quantity of solvent on the enantiomeric ratio.

\begin{tabular}{|c|c|c|c|}
\hline $\begin{array}{c}\text { Organic } \\
\text { component. }\end{array}$ & \begin{tabular}{|c|} 
Average \\
Calculated with the four \\
E values given in Figure \\
2 for each organic \\
component.
\end{tabular} & \begin{tabular}{|c|} 
Standard \\
deviation \\
Calculated \\
with the four \\
E values \\
given in \\
Figure 2 for \\
each organic \\
component. \\
\end{tabular} & $\begin{array}{l}\text { Relative difference (in \%) } \\
\text { between the E values obtained at } \\
\text { the four different } \\
\text { thermodynamic activities of the } \\
\text { organic component. }\end{array}$ \\
\hline A. acetone & 187 & 5 & 3 \\
\hline B. cyclopentane & 197 & 17 & 9 \\
\hline C. $2 \mathrm{M} 2 \mathrm{~B}$ & 218 & 4 & 2 \\
\hline D. 1,4-dioxane & 194 & 13 & 7 \\
\hline E. hexane & 185 & 11 & 6 \\
\hline
\end{tabular}




\section{$\underline{\text { References: }}$}

[1] B. Schulze and M.G. Wubbolts, Curr. Opin. Biotechnol. 10 (1999) 609-615.

[2] E.J. Ariëns, Med. Res. Rev. 6 (1986) 451-456.

[3] I.W. Wainer, Drug strereochemistry, Analytical methods and pharmacology, 2nd edition, Marcel Dekker, New York, 1993.

[4] N.M. Maier, P. Franco and W. Lindner, J. Chrom. A 906 (2001) 3-33.

[5] F. Haeffner, T. Norin and K. Hult, Biophys.J. 74 (1998) 1251-1262.

[6] C. Orrenius, F. Haeffner, D. Rottici, N. Ohrner, T. Norin and K. Hult, Biocatal. Biotrans. $16(1998) 1-15$.

[7] J. Uppenberg, M.T. Hansen, S. Patkar and T.A. Jones, Structure 2 (1994) 293-308.

[8] J. Uppenberg, N. Ohrner, M. Norin, K. Hult, G.J. Kleywegt, S. Patkart, V. Waagen, T. Anthonsen and T.A. Jones, Biochemistry 34 (1995) 16838-16851.

[9] H. Frykman, N. Ohrner, T. Norin and K. Hult, Tetrahedron Lett. 34 (1993) 1367-1370.

[10] C. Orrenius, T. Norin, K. Hult and G. Carrea, Tetrahedron-Asymmetry 6 (1995) 30233030 .

[11] D. Rotticci, C. Orrenius, K. Hult and T. Norin, Tetrahedron: Asymmetry 8 (1997) 359362 .

[12] A. Overmeyer, S. Schrader-Lippelt, V. Kasche and G. Brunner, Biotechnol. Lett. 21 (1999) 65-69.

[13] E.M. Anderson, K.M. Larsson and O. Kirk, Biocatal. Biotrans. 16 (1998) 181-204.

[14] R.J. Kazlauskas, A.N.E. Weissfloch, A.T. Rappaport and L.A. Cuccia, J. Org. Chem. 56 (1991) 2656-2665.

[15] C. Brunet. Université de La Rochelle, La Rochelle 2000.

[16] R.S. Phillips, Enzyme Microb. Technol. 14 (1992) 417-419.

[17] D. Tawaki and A.M. Klibanov., J. Am. Chem. Soc. 114 (1992) 1882-1884.

[18] C.R. Wescott and A.M. Klibanov, J. Am. Chem. Soc. 115 (1993) 1629-1631.

[19] P.A. Fitzpatrick and A.M. Klibanov, J. Am. Chem. Soc. 113 (1991) 3166-3171.

[20] S. Ueji, R. Fujino, N. Okubo, T. Miyazawa, S. Kurita, M. Kitadani and A. Muromatsu, Biotechnol. Lett. 14 (1992) 163-168.

[21] R. Bovara, G. Carrea, L. Ferrara and S. Riva, Tetrahedron: Asymmetry 2 (1991) 931-938.

[22] F. Secundo, S. Riva and G. Carrea, Tetrahedron: Asvmmetrv 3 (1992) 267-280.

[23] A. Ducret, M. Trani and R. Lortie, Enzyme Microb. Technol. 22 (1998) 212-216.

[24] R. Morrone, A. Nicolosi, M. Patti and M. Piattelli, Tetrahedron Asymmetry 6 (1995) 1773-1778.

[25] E. Wehtje, D. Costes and P. Adlercreutz, J. Mol. Catal. B-Enzym. 3 (1997) 221-230.

[26] E. Forro, F. Kanerva and F. Fulop, Tetrahedron Asymmetry 9 (1998) 513-520.

[27] J. Ottosson, L. Fransson, J.W. King and K. Hult, Biochim. Biophys. Acta - Protein Structure and Molecular Enzymology 1594 (2002) 325-334.

[28] J.E. Audia, T.C. Britton, J.J. Droste, B.K. Folmer, G.W. Huffman, V. John, L.H. Latimer, T.E. Mabry, J.S. Nissen, W.J. Porter, J.K. Reel, E.D. Thorsett, J.S. Tung, J. Wu, C.N. Eid and W.L. Scott. 1998.

[29] R.N. Patel, A. Banerjee, V. Nanduri, A. Goswami and F.T. Comezoglu, J. Am. Oil Chem. Soc. 77 (2000) 1015-1019.

[30] D.D. Perrin, W.L.F. Armarengo and D.R. Perrin, Purification of Laboratory Chemicals., Pergamon, Oxford, 1986.

[31] S. Lamare and M.D. Legoy, Biotechnol. Bioeng. 45 (1995) 387-397. 
[32] H.K. Hansen, P. Rasmussen, A. Fredenslund, M. Schiller and J. Gmehling, Ind. Eng. Chem. Res. 30 (1991) 2355-2358.

[33] C.-S. Chen and J.C. Sih, Angewandte Chemie (Int. Ed. Eng). 28 (1989) 695-707.

[34] M.P. Bousquet-Dubouch, M. Graber, N. Sousa, S. Lamare and M.D. Legoy, Biochim. Biophys. Acta 1550 (2001) 90-99.

[35] R.P. Bell, J.E. Critchlow and P. M.I., J. Chem. Soc., Perkin Trans. II (1974) 66-70.

[36] J.B.A. Van Tol, J.B. Odenthal, J.A. Jongejan and J.A. Duine. in (Tramper, J., Vermuë, M.H., Beeftink, H.H. and Von Stockar, U., eds.) Biocatalysis in non-conventional media, Elsevier, Amsterdam 1992, pp. 229-235.

[37] J.B.A. Van Tol, R.M.M. Stevens, W.J. Veldhuizen, J.A. Jongejan and J.A. Duine, Biotechnol. Bioeng. 47 (1995) 71-81.

[38] A.E.M. Janssen, A.M. Vaidya and P.J. Halling, Enzyme Microb. Technol. 18 (1996) 340346.

[39] A.E.M. Janssen, B.J. Sjursnes, A.V. Vakurov and P.J. Halling, Enzyme Microb. Technol. 24 (1999) 463-470.

[40] J. Ottosson and K. Hult, J. Mol. Catal. B-Enzym. 11 (2001) 1025-1028. 